\section{Antibiofilm and Antibacterial Activities of Farnesol and Xylitol as Potential Endodontic Irrigants}

Flávio R. F. Alves ${ }^{1}$, Mônica A. S. Neves' ${ }^{1}$ Marlei G. Silva², Isabela N. Rôças'1, José F. Siqueira Jr. ${ }^{1}$
'Department of Endodontics and Molecular Microbiology Laboratory, Dental School, Estácio de Sá University, Rio de Janeiro, RJ, Brazil ${ }^{2}$ Institute of Microbiology Prof. Paulo de Góes, UFRJ - Federal University of Rio de Janeiro, Rio de Janeiro, RJ, Brazil

Correspondence: Prof. Dr. Flávio R. F. Alves, Avenida Alfredo Baltazar da Silveira, 580/cobertura, Recreio dos Bandeirantes, 22790710 Rio de Janeiro, RJ, Brasil. Tel: +55-21-2497-8988. e-mail: flavioferreiraalves@gmail.com a series of experiments in order to evaluate their potential use as root canal irrigants. The following substances were tested: $0.2 \%$ farnesol; $5 \%$ and $20 \%$ xylitol; $0.2 \%$ farnesol plus $20 \%$ xylitol; and saline (control). For comparison with an established endodontic irrigant, $2.5 \% \mathrm{NaOCl}$ was included in each test. Three experiments were conducted: the crystal violet assay, to evaluate the effects on the biofilm biomass; the dentin disinfection test, to evaluate the effects on bacterial viability in biofilms; and the root canal disinfection test, to simulate the use in the root canal environment. Farnesol was the most effective substance in reducing the biofilm biomass, followed by $20 \%$ xylitol. All substances affected bacterial viability in biofilms; farnesol showed the best results followed by the farnesol/ xylitol combination. Irrigation with all substances significantly reduced the bacterial load $(p<0.001)$, but only the farnesol/xylitol combination was significantly more effective than saline $(p=0.02)$. $\mathrm{NaOCl}$ was more effective than any other substance tested in the three experiments $(p<0.001)$. The findings demonstrated that farnesol affected both the biofilm biomass and the viability of cells in the biofilm, while $20 \%$ xylitol affected only the biofilm biomass. Although not more effective than $\mathrm{NaOCl}$, the combination of these two antibiofilm substances has potential to be used in endodontics in certain situations.

Key Words: antibiofilm agents, bacterial biofilm, endodontic irrigation, Enterococcus faecalis.

\section{Introduction}

Apical periodontitis is an infectious disease associated with intraradicular bacterial biofilms (1). The prevalence of bacterial biofilms in the apical part of the root canal system is very high in teeth with either primary or post-treatment apical periodontitis (1). Therefore, endodontic treatment and retreatment in most cases involve management of a biofilm infection. Because biofilms may be very difficult to eliminate and considering that persistent infectious bioburden in the root canal system is the most important barrier to periradicular tissue healing after endodontic treatment (2), special strategies may be required for successful control of endodontic infections.

Mechanical debridement plays an important role in the treatment of biofilms by significantly reducing the bacterial bioburden and removing organic matter that might hamper the antimicrobial effects of irrigants. Debridement is essential to remove endodontic biofilms, but the fact that instrumentation leaves several untouched areas in the root canal indicates that biofilms may remain unaffected in these areas (3). Biofilms have the ability to reconstitute themselves after being partially affected (4), which makes mechanical debridement alone insufficient in endodontic therapy. This reinforces the need of using antimicrobial and/or antibiofilm agents as irrigants.

Sodium hypochlorite $(\mathrm{NaOCl})$ has strong bactericidal and antibiofilm properties (5-6). However, it is highly cytotoxic (7) and its effects are significantly affected by organic matter (8). It was also shown that the clinical performance of $\mathrm{NaOCl}$ is inferior to its effects in vitro and about $40-60 \%$ of the cases of irrigation with $\mathrm{NaOCl}$ still harbor bacteria in the main canal (2). Moreover, $\mathrm{NaOCl}$ and other nonspecific antimicrobials used in traditional endodontic treatment may cause significant changes in dentin that further interfere with pulp regeneration approaches (9).

Multiple and concurrent strategies may be the most effective way of eliminating biofilms. For instance, attempts to combine different strategies to suppress biofilms in chronic wound infections include mechanical debridement, antimicrobial agents (antibiotics, antiseptics and disinfectants), and antibiofilm agents (4). Examples of antibiofilm agents include those targeting bacterial attachment (lactoferrin), blocking formation or degrading the biofilm matrix (xylitol and farnesol), and disrupting quorum-sensing systems (quorum sensing inhibitors).

Trans-trans farnesol (tt-farnesol) is a sesquiterpene alcohol commonly found in propolis and in essential oils of citrus fruits (e.g., in orange peel and lemon-grass oil). Farnesol has demonstrated to have antibiofilm effects by either preventing biofilm formation or attacking established biofilms. Farnesol inhibits or reduces biofilm 
formation by diverse microbial species, including Candida albicans, Streptococcus mutans and Staphylococcus aureus (10-12). This substance inhibits acid production and glucan synthesis by S. mutans in biofilms (12). Biofilms formed in the presence of farnesol contain less biomass, and display marked changes in matrix composition (13). Topical applications of farnesol reduce the biofilm matrix content (14). In addition to affecting the biofilm structure by reducing its biomass, farnesol seems to kill bacteria in biofilms, depending on the concentration (13).

Xylitol is a five-carbon alcohol sugar found naturally in small quantities in fruit and vegetables. It is commonly used in chewing gum, with preventive effects on caries, and has been shown to inhibit biofilm formation (15). Biofilms treated with xylitol exhibit weakened overall structure (16). Xylitol can act synergistically with farnesol and the combination with this substance can selectively inhibit the growth of S. aureus (15).

This study investigated the antibiofilm and antibacterial effects of farnesol and xylitol in a series of experiments to evaluate their potential to be used as endodontic irrigants.

\section{Material and Methods}

\section{Substances}

The substances and combinations tested in this study were the following: 0.2\% farnesol (Sigma-Aldrich, St. Louis, MO, USA); 5\% and 20\% xylitol (Sigma-Aldrich); and $0.2 \%$ farnesol plus $20 \%$ xylitol. For comparison with an established endodontic irrigant, $2.5 \% \mathrm{NaOCl}$ was included in each test for a separate analysis. Sterile $0.85 \%$ saline was used as control for all experiments. As extracted human teeth were used in two experiments, the study protocol was subjected to and approved by the Ethics Committee of the Estácio de Sá University (Process\#0248).

\section{Crystal Violet Assay}

Biofilm biomass was visualized and quantified by a crystal violet binding assay as previously described $(17,18)$. A $0.5 \mathrm{McF}$ arland standard of an overnight culture of Enterococcus faecalis ATCC 29212 was prepared in Tryptic Soy Broth (TSB, Difco, Detroit, MI, USA) supplemented with $1 \%$ glucose (Merck, Whitehouse Station, NJ, USA). After agitation in vortex, $200 \mu \mathrm{L}$ aliquots were distributed in wells of a 96-well microtiter plate (tissue-culture-treated polystyrene, flat bottoms, model 92096 TPP "Techno Plastic Products", Trasadingen, Switzerland), and incubated for 24 $h$ at $35^{\circ} \mathrm{C}$. Next, the content of each well was aspirated, and the wells were rinsed three times with $200 \mu \mathrm{L}$ of phosphatebuffered saline (PBS, pH 7.2) to remove loosely attached cells. Each test substance was applied $(200 \mu \mathrm{L}$ per well) for 1,3 and $10 \mathrm{~min}$ at $37^{\circ} \mathrm{C}$. After washing three times with PBS, adherent bacteria were stained for 20 min with $200 \mu \mathrm{L}$ of $0.1 \%$ violet crystal solution at room temperature. Excess stain was rinsed off by copious washing with distilled water. Plates were overturned and air-dried, and the dye bound to the adherent cells was solubilized with $150 \mu \mathrm{L}$ of $95 \%$ ethanol for $5 \mathrm{~min}$. For quantification of biofilm biomass remaining after exposure to the test solutions, absorbance of the crystal violet solution was measured using an ELISA reader model 680 (Bio-Rad Laboratories, Hercules, CA, USA) at a wavelength of $590 \mathrm{~nm}$. Positive control consisted of saline used instead of the test substance. Negative control used sterile culture broth. All assays were performed with 4 repetitions and on three separate occasions. The cut-off value for optical density (OD) measurements was defined as three standard deviations above the mean OD of the negative control (17). Therefore, final OD values for the test substances were expressed as average $O D$ value reduced by the cutt-off value.

\section{Dentin Disinfection Assay}

Root hemicylinders were prepared by cutting off the tooth crown and the apical part of the root of extracted maxillary incisors and canines to obtain $5-\mathrm{mm}$ cylinders. The root canals were enlarged up to a \#5 Gates-Glidden bur and then the cylinders were split to generate two hemisections. The root hemicylinders were immersed in fresh TSB, sterilized in an autoclave and contaminated with E. faecalis ATCC 29212 for 30 days at $37^{\circ} \mathrm{C}$. Culture medium was replenished every week. Excess culture medium was removed and the specimens were washed by gentle shaking in saline solution to remove nonadhered cells. Four hemicylinders were prepared for scanning electron microscopy (SEM) as described previously (19) to confirm biofilm formation. Five hemicylinders were immersed in each test solution or saline (control) for $3 \mathrm{~min}$ at $37^{\circ} \mathrm{C}$. Next, the hemicylinders were transferred to flasks containing saline solution for $1 \mathrm{~min}$. Specimens were placed in 5\% sodium thiosulphate for $1 \mathrm{~min}$, then in $1 \mathrm{~mL}$ of sterile saline, and subjected to ultrasonic agitation for $2 \mathrm{~min}$ in order to loosen the biofilm. After agitation in vortex, aliquots were immediately processed for culture. Samples were tenfold serially diluted in saline, aliquots of $100 \mu \mathrm{L}$ were plated onto Mitis-Salivarius agar plates (Difco), and then incubated at $37^{\circ} \mathrm{C}$ for $48 \mathrm{~h}$. The grown colony forming units (CFU) were counted and then transformed into actual counts based on the known dilution factors.

\section{Root Canal Disinfection Assay}

This experiment used 55 single-rooted teeth (maxillary central incisors and canines), extracted for reasons not related to this study. All teeth were sectioned to leave a 10-mm long root segment.

Root canals were prepared as follows: LA Axxess burs 
\#45 (SybronEndo, Orange, CA, USA) were used along the coronal two-thirds and then the apical root canal was instrumented up to a \#50 K-type file $1 \mathrm{~mm}$ beyond the apical foramen. All preparation procedures were performed under continuous irrigation with water. The teeth were immersed in TSB (Difco), ultrasonicated for 1 min to release the entrapped air and allow penetration of the culture media into root canal irregularities, and then sterilized in an autoclave for $20 \mathrm{~min}$ at $121^{\circ} \mathrm{C}$.

E. faecalis strain ATCC 29212 was used for root canal contamination for 30 days at $37^{\circ} \mathrm{C}$ under gentle shaking. Culture media was replenished every week. Following the contamination period, all teeth had the excess of culture medium dripped off and their external root surface wiped with sterile gauze. The teeth were divided into 5 groups $(n=11) ; 5 \%$ xylitol was not tested in this experiment. The apical foramen of each tooth was sealed with a fast setting epoxy resin to prevent apical bacterial leakage and create a closed-end channel that produced a vapor lock effect. Teeth were mounted vertically up to the cervical region in blocks made of a silicone impression material (President Jet; Coltène AG, Cuyahoga Falls, OH, USA). The tooth crown, including the pulp chamber walls, and the silicone surface solution to remove unattached cells and an initial sample (S1) was taken by the sequential use of 3 to 5 paper points placed to the WL. Each paper point remained in the canal for $1 \mathrm{~min}$. Paper points were transferred to tubes containing $1 \mathrm{~mL}$ of sterile saline and immediately processed.

Next, the root canals were irrigated with $2 \mathrm{~mL}$ of the

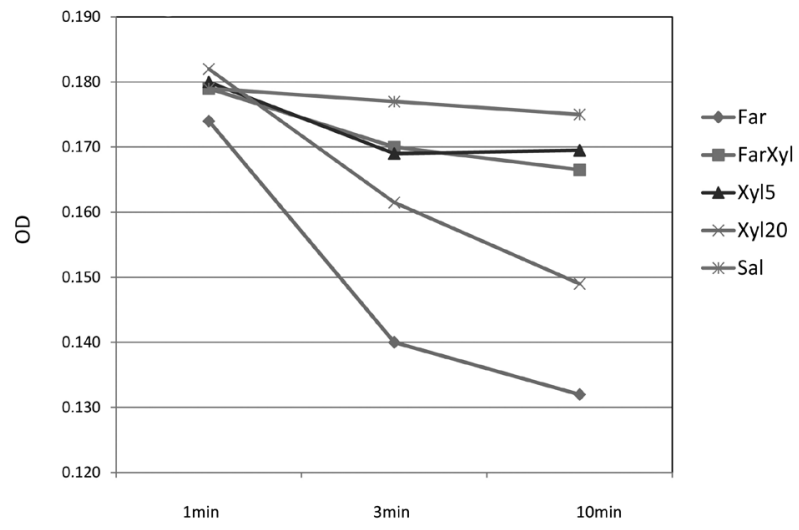

Figure 1. Data from the crystal violet assay, demonstrating the timedependent effects of the substances on the biomass of Enterococcus faecalis biofilms. Xyl5 (5\% xylitol); Xyl20 (20\% xylitol); Far (0.2\% farnesol); FarXyl (0.2\% farnesol/20\% xylitol); Sal (saline). test substances. Irrigation was performed with disposable syringes and 30-gauge NaviTip needles (Ultradent, South Jordan, UT, USA) taken up to $3 \mathrm{~mm}$ of the WL. The canal was then flooded with the tested irrigant, which was sonically agitated for $1 \mathrm{~min}$ by using the EndoActivator blue tip size \#35/.04 (Dentsply Tulsa Dental, Tulsa, OK, USA) placed up to $2 \mathrm{~mm}$ of the $W \mathrm{~L}$, at $10,000 \mathrm{cpm}$. Then the canals were again irrigated with $3 \mathrm{~mL}$ of the same test solution. After leaving the tested solution for $3 \mathrm{~min}$ in the canal, $1 \mathrm{~mL}$ of sodium thiosulfate was used to rinse the canal and another bacteriological sample (S2) was taken as above. Next, the canals of all groups were irrigated with $5 \mathrm{~mL}$ of $2.5 \%$ $\mathrm{NaOCl}$ for 1 min. $\mathrm{NaOCl}$ was inactivated with $10 \%$ sodium thiosulfate for $1 \mathrm{~min}$ and a third sample (S3) was taken.

Samples were agitated in vortex for $1 \mathrm{~min}$ and immediately processed for culture. After tenfold serial dilutions were done in saline, aliquots of $100 \mu \mathrm{L}$ of each dilution were plated onto Mitis-Salivarius agar plates (Difco), and incubated at $370 \mathrm{C}$ for $48 \mathrm{~h}$. The grown colony forming units (CFU) were counted and then transformed into actual counts based on the known dilution factors.

The Wilcoxon matched pairs test was used for intragroup and the Mann-Whitney $U$ tests for intergroup quantitative analysis. Intragroup evaluation related to the reduction in E. faecalis counts from S1 to S2 or S3; and from S2 to S3. Since no significant differences were found between S1 samples from the groups (Mann-Whitney U test), data for intergroup quantitative comparisons consisted of the absolute counts in S2 and S3. Significance level for all analyses was set at $p<0.05$.

\section{Results}

\section{Crystal Violet Assay}

This test evaluated the effects of the substances on the

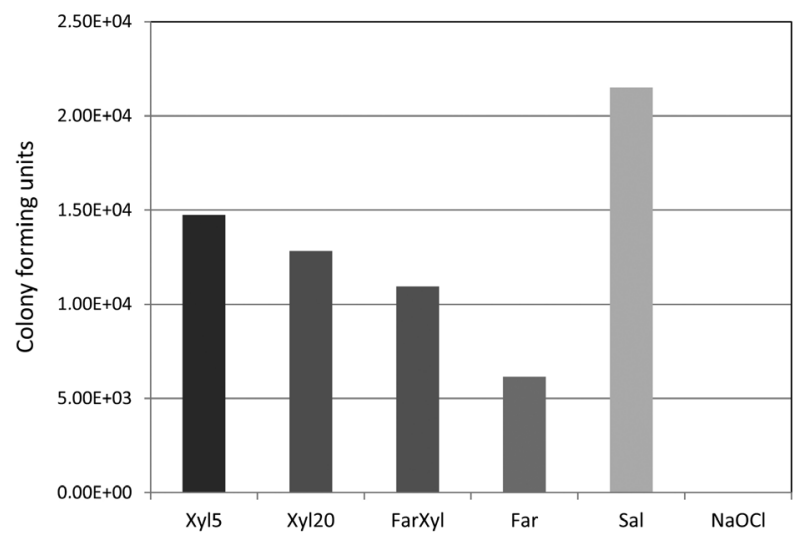

Figure 2. Mean number of colony forming units after exposure of Enterococcus faecalis biofilms grown on dentin hemicylinders to the tested substances. Xyl5 (5\% xylitol); Xyl20 (20\% xylitol); Far (0.2\% farnesol); FarXyl ( $0.2 \%$ farnesol/20\% xylitol); Sal (saline). 
biofilm biomass. The test strain of E. faecalis was shown to form biofilms in this assay. All substances managed to reduce the biofilm biomass when compared to controls and the effects were time-dependent (Fig. 1). After $1 \mathrm{~min}$ of exposure, the effects of all substances were virtually negligible. After $3 \mathrm{~min}$, all of them reduced the biofilm biomass. A further reduction in biomass was observed after $10 \mathrm{~min}$, except for 5\% xylitol. After both 3 and 10 $\mathrm{min}$, the most effective substance was farnesol followed by $20 \%$ xylitol. All of the test substances were substantially less effective than $2.5 \% \mathrm{NaOCl}$ in all time intervals (data not shown).

\section{Dentin Disinfection Assay}

This test evaluated the effects of the test substances on the viability of bacteria present in biofilms adhered to dentin. SEM confirmed biofilm formation by $E$. faecalis on dentin from the root hemicylinders (data not shown). In this test, all substances promoted reduction in the number of bacterial cells when compared with saline (Fig. 2). The greatest reduction was obtained with farnesol, followed by the farnesol/xylitol combination. No fragment exposed to $\mathrm{NaOCl}$ showed bacterial growth.

\section{Root Canal Disinfection}

This test intended to simulate the use of the antibiofilm substances in the root canal environment. Means, medians and ranges for all groups are shown in Table 1. Intragroup analysis revealed that irrigation with all substances, including saline (control), succeeded in significantly reducing the bacterial load $(p<0.001)$. However, intergroup analysis of $\mathrm{S} 2$ samples demonstrated that only the farnesol/ xylitol combination caused a reduction in bacterial counts that was significantly higher than saline $(p=0.02)$. When $\mathrm{NaOCl}$ entered the analysis, data revealed that this substance was significantly more effective than every other tested substance $(p<0.001)$. When a supplementary irrigation with $2.5 \% \mathrm{NaOCl}$ was performed, intragroup analysis ( $\mathrm{S} 2 \times \mathrm{S} 3$ comparison) indicated that bacterial levels were still significantly reduced, regardless of the group $(p<0.001)$. When comparing S3 samples between groups, both farnesol $+\mathrm{NaOCl}$ and farnesol/xylitol $+\mathrm{NaOCl}$ were significantly more effective than saline $+\mathrm{NaOCl}(p=0.02)$. The combination of $\mathrm{NaOCl}+\mathrm{NaOCl}$ was not more effective than either farnesol $+\mathrm{NaOCl}$ or farnesol/xylitol $+\mathrm{NaOCl}$ ( $>00.05$ ).

\section{Discussion}

Because biofilms are very frequently observed in the apical root canal system of teeth with apical periodontitis, they should be regarded as targets in endodontic treatment. At present, the most effective treatment of medical biofilms in different body sites is its physical removal by debridement. This is also true for endodontic treatment, as instrumentation may affect most biofilms present in the main root canal. However, biofilms may remain

Table 1. Enterococcus faecalis counts before (S1), after irrigation with antibiofilm agents (S2), and after a final rinse with 2.5\% $\mathrm{NaOCl}(\mathrm{S} 3)$

\begin{tabular}{|c|c|c|c|c|c|c|c|c|c|}
\hline \multirow{2}{*}{ Groups } & \multicolumn{3}{|c|}{ S1 } & \multicolumn{3}{|c|}{ S2 } & \multicolumn{3}{|c|}{ S3 } \\
\hline & Mean & Median & Range & Mean & Median & Range & Mean & Median & Range \\
\hline Saline & $5.08 \mathrm{E}+05$ & $5.12 \mathrm{E}+05$ & $\begin{array}{c}1.00 \mathrm{E}+03 \\
-1.50 \mathrm{E}+06\end{array}$ & $1.45 \mathrm{E}+04^{\mathrm{a}}$ & $1.34 \mathrm{E}+04$ & $\begin{array}{c}6.20 \mathrm{E}+02 \\
-2.88 \mathrm{E}+04\end{array}$ & $5.51 \mathrm{E}+02^{\mathrm{d}}$ & $4.00 \mathrm{E}+01$ & $\begin{array}{c}0 \\
-2.56 E+03\end{array}$ \\
\hline $20 \%$ xylitol & $2.08 \mathrm{E}+05$ & $1.20 \mathrm{E}+05$ & $\begin{array}{c}9.00 \mathrm{E}+03 \\
-4.96 \mathrm{E}+05\end{array}$ & $9.76 \mathrm{E}+03^{\mathrm{a}}$ & $1.09 \mathrm{E}+04$ & $\begin{array}{c}3.00 \mathrm{E}+02 \\
-2.50 \mathrm{E}+04\end{array}$ & $5.18 \mathrm{E}+01^{\mathrm{d}}$ & 0 & $\begin{array}{c}0 \\
-3.10 \mathrm{E}+02\end{array}$ \\
\hline $0.2 \%$ farnesol & $7.04 \mathrm{E}+04$ & $4.64 \mathrm{E}+04$ & $\begin{array}{c}1.30 \mathrm{E}+03 \\
-1.76 \mathrm{E}+05\end{array}$ & $1.02 \mathrm{E}+04^{\mathrm{a}}$ & $1.20 \mathrm{E}+04$ & $\begin{array}{c}3.80 \mathrm{E}+02 \\
-2.37 \mathrm{E}+04\end{array}$ & $8.18 \mathrm{E}+00 \mathrm{~d}, \mathrm{e}$ & 0 & $\begin{array}{c}0 \\
-8.00 E+01\end{array}$ \\
\hline $\begin{array}{l}0.2 \% \text { farnesol/ } \\
20 \% \text { xylitol }\end{array}$ & $3.66 \mathrm{E}+05$ & $2.90 \mathrm{E}+04$ & $\begin{array}{c}2.00 \mathrm{E}+03 \\
-2.69 \mathrm{E}+06\end{array}$ & $6.35 \mathrm{E}+03 \mathrm{a,b}$ & $5.28 \mathrm{E}+03$ & $\begin{array}{c}7.10 \mathrm{E}+02 \\
-1.60 \mathrm{E}+04\end{array}$ & $3.64 \mathrm{E}+00 \mathrm{~d}, \mathrm{e}$ & 0 & $\begin{array}{c}0 \\
-2.00 \mathrm{E}+01\end{array}$ \\
\hline $2.5 \% \mathrm{NaOCl}$ & $8.01 \mathrm{E}+05$ & $5.76 \mathrm{E}+05$ & $\begin{array}{c}2.00 \mathrm{E}+04 \\
-1.98 \mathrm{E}+06\end{array}$ & $5,67 \mathrm{E}+01 \mathrm{a}, \mathrm{b}, \mathrm{c}$ & 0 & $0-5.10 \mathrm{E}+02$ & $0 \mathrm{~d}, \mathrm{e}$ & 0 & 0 \\
\hline
\end{tabular}

a Significant difference when compared to S1 of the respective group. ${ }^{\mathrm{b}}$ Significant difference when compared to S2 from the saline group. c Significant difference when compared to S2 from all the other groups. d Significant difference when compared to S2 from the respective group. ${ }^{\text {e Significant }}$ difference when compared to S3 from the saline group. 
unaffected in areas of the main canal that were untouched by instruments and in areas distant from the main canal where instruments cannot reach, such as isthmuses and apical/lateral ramifications (20). Residual biofilms may lead to persistent apical periodontitis (2). Therefore, there is need for chemical substances as irrigants or interappointment medications that have both antibacterial and antibiofilm activities. In the present study it was investigated the antibiofilm and antibacterial effects of farnesol and xylitol against $E$. faecalis biofilms in three experiments. These substances have previously shown to be effective against biofilms and have been suggested for use as potential auxiliary substances in the treatment of biofilms associated with chronic wound infections (21) or caries (22).

The findings in this study demonstrated that farnesol was effective in both reducing the biofilm biomass and killing bacteria in biofilms. Farnesol has previously shown to have antibacterial effects (11). Farnesol is hydrophobic and may accumulate on the bacterial cell membranes, compromising their integrity and leading to a consequent release of the intracellular content $(11,13)$. Even in noninhibitory concentrations, farnesol induces a decrease in biofilm matrix production and affects biofilm formation
When used alone, xylitol had significant effects on the biofilm biomass only at the $20 \%$ concentration. Regardless of the concentration, its effects on bacterial viability were minimal. These findings agree with a previous study that showed that xylitol has a minimal influence on the viability of bacterial cells within biofilms and its antibiofilm effects are probably related to disruption of the biofilm structure (16). When 20\% xylitol was combined with farnesol, good results were observed for the test simulating use in the root canal, as this combination was the only one to show significant bacterial reduction when compared with saline. Xylitol has shown to act synergistically with farnesol in terms of antibacterial and antibiofilm activities (15).

The test substances were significantly less effective than $\mathrm{NaOCl}$ in either reducing the biofilm biomass or killing bacteria in biofilms. This comes as no surprise, as $\mathrm{NaOCl}$ is a potent disinfectant with recognized strong bactericidal and antibiofilm properties $(5,6)$. However, $\mathrm{NaOCl}$ has several disadvantages, including its cytotoxicity to vital tissues, foul smell and taste, and the capacity to bleach clothes and corrode metal objects (24). In addition, it may alter the dentin structure and leave residues that may interfere with pulp regeneration procedures and bonding of adhesive materials to dentin (9). Thus, the search for safer (and more effective) substances to be used as root canal irrigants should be encouraged.

In the root canal experiment, an attempt was made to evaluate the effects of using the antibiofilm substances first to attack the biofilm biomass, and then to perform further irrigation with $\mathrm{NaOCl}$, which would supposedly act on a more vulnerable residual biofilm. Although attractive, this protocol did not work as expected, because it was not more effective than the group where $\mathrm{NaOCl}$ was used throughout the preparation phase, i.e., without pre-irrigation with the antibiofilm agents. It remains to be determined whether this approach may work out with other irrigants less effective against the biofilm biomass but more biocompatible than $\mathrm{NaOCl}$, such as chlorhexidine.

The present findings suggest that farnesol alone or in combination with xylitol may be a potential endodontic irrigant with antibiofilm properties. Both substances are natural products and have the potential to be more biocompatible than $\mathrm{NaOCl}$. Farnesol has shown to be devoid of toxic and mutagenic effects (25). Further studies are required to assess its biocompatibility when used in vivo.

In conclusion, the findings of the present study demonstrated that farnesol affected both the biofilm biomass and the viability of cells in the biofilm, while $20 \%$ xylitol affected the biofilm biomass. Combination of these two antibiofilm substances has potential to be used in endodontic treatment to eliminate biofilms. Further studies are required to evaluate other biological properties of these substances before clinical use can be indicated.

\section{Resumo}

Este estudo investigou os efeitos antibiofilme e antibacteriano de farnesol e xilitol em uma série de experimentos para avaliar seu uso potencial como irrigante de canais radiculares. As seguintes substâncias foram testadas: farnesol a 0,2\%; xilitol a 5\% e 20\%; farnesol a 0,2\% combinado com xilitol a $20 \%$; e solução salina (controle). $\mathrm{NaOCl}$ foi testado para comparação. Três experimentos foram conduzidos: o teste do cristal violeta para avaliar os efeitos sobre a biomassa de biofilme, 0 teste da desinfecção de fragmentos de dentina para avaliar os efeitos na viabilidade bacteriana nos biofilmes e o teste da desinfecção de canal radicular para simular o uso no ambiente do canal radicular. Farnesol foi o mais eficaz, seguido por xylitol a 20\%. Todas as substâncias afetaram a viabilidade bacteriana nos biofilmes; farnesol mostrou os melhores resultados, seguido pela combinação farnesol/xilitol. A irrigação com todas as substâncias reduziu significativamente a carga bacteriana $(p<0,001)$, mas somente a combinação farnesol/xilitol foi significativamente mais eficaz que a solução salina $(p=0,02)$. $\mathrm{NaOCl}$ foi mais eficaz que qualquer outra substância testada nos três experimentos $(p<0,001)$. Os achados demonstraram que farnesol afetou tanto a biomassa de biofilme quanto a viabilidade das células no biofilme, enquanto que xilitol a $20 \%$ afetou a biomassa de biofilme. Embora não mais eficazes que $\mathrm{NaOCl}$, combinações dessas duas substâncias antibiofilmes têm o potencial de ser usadas na Endodontia, em determinadas situações.

\section{Acknowledgements}

This study was supported by grants from Fundação Carlos Chagas Filho de Amparo à Pesquisa do Estado do Rio de Janeiro (FAPERJ) and Conselho 
Nacional de Desenvolvimento Científico e Tecnológico (CNPq), Brazilian Government Institutions. The authors are grateful to Dr. Clifford Ruddle for providing the EndoActivator system. The authors deny any conflicts of interest.

\section{References}

1. Ricucci $D$, Siqueira JF, Jr. Biofilms and apical periodontitis: study of prevalence and association with clinical and histopathologic findings. J Endod 2010;36:1277-1288.

2. Siqueira JF, Jr., Rôças IN. Clinical implications and microbiology of bacterial persistence after treatment procedures. J Endod 2008;34:1291-1301.

3. Paque F, Balmer M, Attin T, Peters OA. Preparation of oval-shaped root canals in mandibular molars using nickel-titanium rotary instruments: a micro-computed tomography study. J Endod 2010;36:703-707.

4. Wolcott $\mathrm{R}$, Dowd $\mathrm{S}$. The role of biofilms: are we hitting the right target? Plast Reconstr Surg 2011;127Suppl 1:28S-35S.

5. Siqueira JF, Jr, Batista MM, Fraga RC, de Uzeda M. Antibacterial effects of endodontic irrigants on black-pigmented gram-negative anaerobes and facultative bacteria. J Endod 1998;24:414-416.

6. Ordinola-Zapata R, Bramante CM, Cavenago B, Graeff MS, Gomes de Moraes I, Marciano M, Duarte MA. Antimicrobial effect of endodontic solutions used as final irrigants on a dentine biofilm model. Int Endod J 2012;45:162-168.

7. Pashley EL, Birdsong NL, Bowman K, Pashley DH. Cytotoxic effects of $\mathrm{NaOCl}$ on vital tissue. J Endod 1985;11:525-528.

8. Pappen FG, Qian W, Aleksejuniene J, Leonardo R de T, Leonardo MR, Haapasalo M. Inhibition of sodium hypochlorite antimicrobial activity in the presence of bovine serum albumin. J Endod 2010;36:268-271.

9. Fouad AF. The microbial challenge to pulp regeneration. Adv Dent Res 2011;23:285-289.

10. Ramage G, Saville SP, Wickes BL, Lopez-Ribot JL. Inhibition of Candida albicans biofilm formation by farnesol, a quorum-sensing molecule. Appl Environ Microbiol 2002;68:5459-5463.

11. Jabra-Rizk MA, Meiller TF, James CE, Shirtliff ME. Effect of farnesol on Staphylococcus aureus biofilm formation and antimicrobial susceptibility. Antimicrob Agents Chemother 2006;50:1463-1469.

12. Koo H, Schobel B, Scott-Anne K, Watson G, Bowen WH, Cury JA, et al.. Apigenin and tt-farnesol with fluoride effects on S. mutans biofilms and dental caries. J Dent Res 2005;84:1016-1020.

13. Gomes F, Teixeira P, Cerca N, Azeredo J, Oliveira R. Effect of farnesol on structure and composition of Staphylococcus epidermidis biofilm matrix. Curr Microbiol 2011;63:354-359.
14. Jeon JG, Pandit S, Xiao J, Gregoire S, Falsetta ML, Klein MI, et al.. Influences of trans-trans farnesol, a membrane-targeting sesquiterpenoid, on Streptococcus mutans physiology and survival within mixed-species oral biofilms. Int J Oral Sci 2011;3:98-106.

15. Katsuyama $M$, Ichikawa $H$, Ogawa $S$, Ikezawa $Z$. A novel method to control the balance of skin microflora. Part 1. Attack on biofilm of Staphylococcus aureus without antibiotics. J Dermatol Sci 2005;38:197-205.

16. Ammons MC, Ward LS, Fisher ST, Wolcott RD, James GA. In vitro susceptibility of established biofilms composed of a clinical wound isolate of Pseudomonas aeruginosa treated with lactoferrin and xylitol. Int J Antimicrob Agents 2009;33:230-236.

17. Stepanovic S, Vukovic D, Hola V, Di Bonaventura G, Djukic S, Cirkovic I, et al.. Quantification of biofilm in microtiter plates: overview of testing conditions and practical recommendations for assessment of biofilm production by staphylococci. APMIS 2007;115:891-899.

18. Alves FR, Silva MG, Rôças IN, Siqueira JF, Jr. Biofilm biomass disruption by natural substances with potential for endodontic use. Braz Oral Res 2013;27:20-25.

19. Alves FR, Almeida BM, Neves MA, Moreno JO, Rôças IN, Siqueira JF, Jr. Disinfecting oval-shaped root canals: effectiveness of different supplementary approaches. J Endod 2011;37:496-501.

20. Ricucci $\mathrm{D}$, Siqueira JF, Jr. Apical actinomycosis as a continuum of intraradicular and extraradicular infection: case report and critical review on its involvement with treatment failure. J Endod 2008;34:1124-1129.

21. Rhoads DD, Wolcott RD, Percival SL. Biofilms in wounds: management strategies. J Wound Care 2008;17:502-508.

22. Koo H, Jeon JG. Naturally occurring molecules as alternative therapeutic agents against cariogenic biofilms. Adv Dent Res 2009;21:63-68.

23. Unnanuntana $A$, Bonsignore L, Shirtliff ME, Greenfield EM. The effects of farnesol on Staphylococcus aureus biofilms and osteoblasts. An in vitro study. J Bone Joint Surg Am 2009;91:2683-2692.

24. Siqueira JF, Jr. Treatment of endodontic infections. London: Quintessence Publishing, 2011.

25. Goncalves O, Pereira R, Goncalves F, Mendo S, Coimbra MA, Rocha SM. Evaluation of the mutagenicity of sesquiterpenic compounds and their influence on the susceptibility towards antibiotics of two clinically relevant bacterial strains. Mutat Res 2011;723:18-25.

Received February 25, 2013 Accepted April 10, 2013 